\title{
MISSE 5 Thin Films Space Exposure Experiment
}

Gale A. Harvey, William H. Kinard, and James L. Jones

NASA Langley Research Center

Hampton, VA 23681-2199

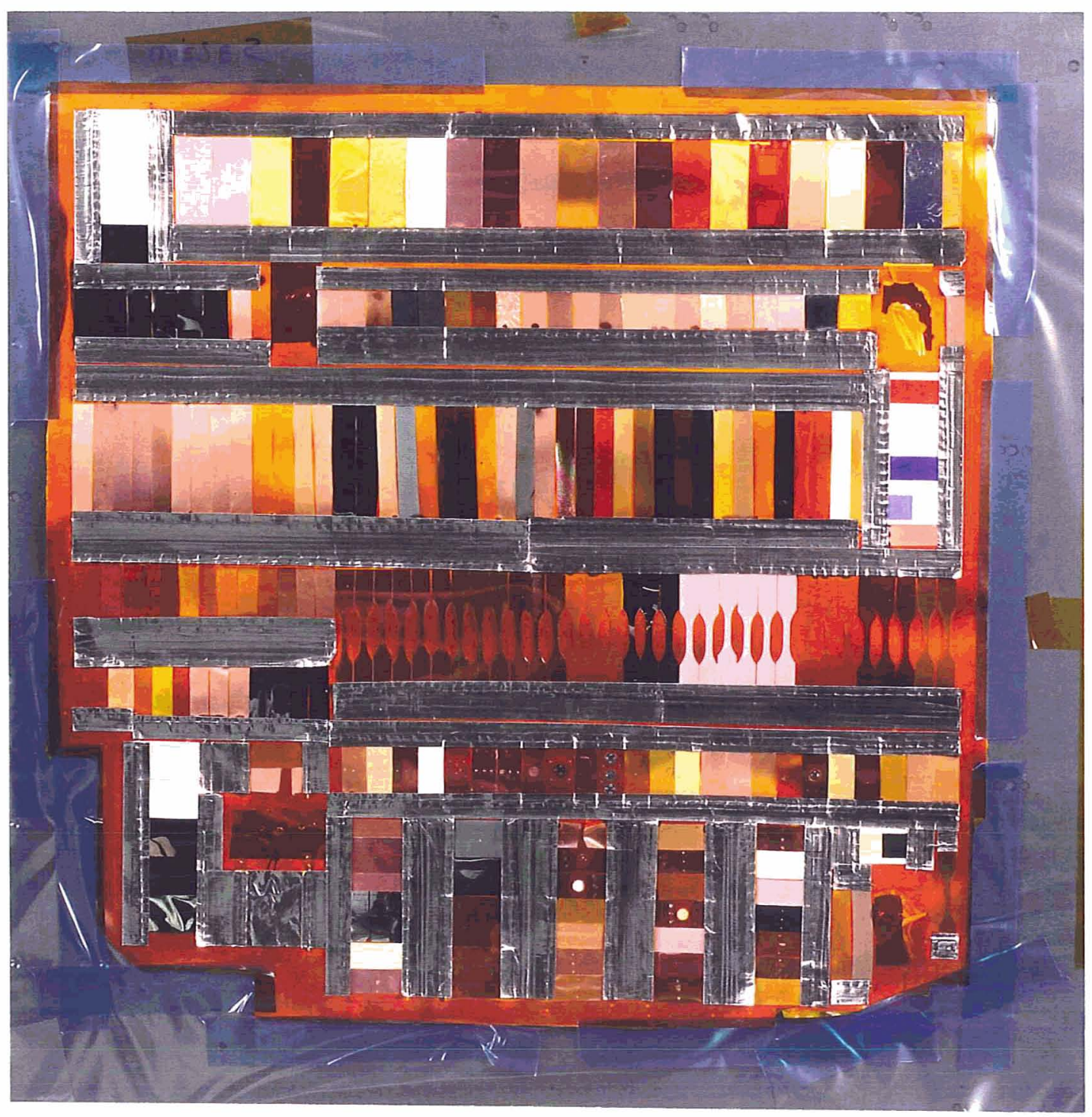

AIAA Space 2007 Conference \& Exposition Long Beach, CA September 2007 


\title{
MISSE 5 Thin Films Space Exposure Experiment
}

\author{
Gale A. Harvey ${ }^{1}$, William H. Kinard ${ }^{2}$, and James L. Jones ${ }^{3}$ \\ NASA Langley Research Center, Hampton, VA, 23681
}

\begin{abstract}
The Materials International Space Station Experiment (MISSE) is a set of space exposure experiments using the International Space Station (ISS) as the flight platform. MISSE 5 is a co-operative endeavor by NASA-LaRC, United Stated Naval Academy, Naval Center for Space Technology (NCST), NASA-GRC, NASA-MSFC, Boeing, AZ Technology, MURE, and Team Cooperative. The primary experiment is performance measurement and monitoring of high performance solar cells for U. S. Navy research and development. A secondary experiment is the telemetry of this data to ground stations. A third experiment is the measurement of low-Earth-orbit (LEO) low-Sun-exposure space effects on thin film materials. Thin films can provide extremely efficacious thermal control, designation, and propulsion functions in space to name a few applications. Solar ultraviolet radiation and atomic oxygen are major degradation mechanisms in LEO. This paper is an engineering report of the MISSE 5 thin films 13 months space exposure experiment.
\end{abstract}

\section{Introduction}

The International Space Station (ISS) (Figure 1) is a key element of the NASA Human Exploration and Development of Space Enterprise. The ISS will expand our knowledge and help bring the benefits of space to Earth. The first element of the ISS was launched in November 1998. The ISS became inhabited in October 2000. The ISS is scheduled for completion in the 2010 timeframe.

The Long Duration Exposure Facility (LDEF) and the Mir Environmental Effects Payload (MEEP) utilized hardware returned from low-Earth-orbit (LEO) to study and measure space and spacecraft induced environmental effects. A section of a solar array returned from the Mir space station has also been extensively studied for power degradation, micrometeoroid, and contamination effects.

Numerous papers, including references 1-6, have been written on analyses of the returned hardware. The LDEF had more than 5 years space exposure, the MEEP hardware had more than one year space exposure, and the returned Mir solar array had more than ten years of space exposure.

The space exposed materials of the MEEP experiment were housed in suitcase-like Payload Experiment Containers (PECs) (Figure 2) for transporting to and from Mir via the Shuttle Orbiter. Four of these PECs were clamped to handrails of the Mir-Orbiter docking module. These PECs were refurbished, and PECs 1 and 2 were deployed on the ISS August 10, 2001. These two PECs were retrieved July 30, 2005. PECs 3 and 4 were deployed on the ISS July 2006 and are expected to be retrieved in late 2007. The experiment trays temperature-measurement system for PECs 1, 2, 3, and 4 is described in reference 7. Experiment tray temperature measurements for PECs 1 and 2 are reported in reference 8. PEC 5 was fabricated in 2003, for an early-opportunity deployment on the ISS. PEC 5 was deployed August 5, 2005 and returned September 15, 2006.

MISSE is being developed as an element of the Engineering Research and Technology Program at Johnson Space Center as an innovative technical concept to expand the utilization of the ISS. It is a cooperative endeavor by the NASA Langley Research Center, NASA Glenn Research Center, NASA Marshal Space Flight Center, NASA Johnson Space Center, the Materials Laboratory at the Air Force Research Laboratory, and the Boeing Phantom works. The objective of MISSE is to evaluate performance, stability, and long term survivability of materials and components planned for use by NASA and DOD on future LEO, synchronous orbit, and interplanetary space missions.

${ }^{1}$ Research Scientist, Systems Engineering Directorate, Mail Stop 424

${ }^{2}$ Senior Research Scientist, Materials and Chemistry Directorate, Mail Stop

${ }^{3}$ Deceased Research Scientist, Materials and Chemistry directorate 


\section{Experiment Constraints and Sample Attachment Methods}

The MISSE 5 primary experiments Provide Communications System in the Amateur Satellite Service for Telemetry Command and Control (PCSat2) and the Forward Technology Solar Cell Experiment (FTSCE). The solar cell experiment requires a Sun-looking orientation for one of the experiment trays. Therefore, the opposite experiment side received little direct Sun exposure. It was desirable to fly (expose to LEO) several hundreds of thin film materials with little Sun exposure in order to separate the effects of solar ultraviolet degradation from atomic oxygen degradation. The materials part of MISSE 5 was tightly constrained in mass (less than one pound) and in volume. These tight constraints in mass and volume also constrained the attachment mechanisms. The thin film attachment method was to secure the samples on a 5 mil thick Kapton sheet with $1 / 4$ inch wide high temperature acrylic transfer tape at each end of the samples. One mil thick, 1/2 -inch wide Kapton tape strips were then placed over the last $1 / 4$-inch of each sample and on1/4-inch of the Kapton sheet as the second attachment method. Approximately 1/8-inch long stitches are then sown through the sample, 5 mil Kapton sheet, transfer tape, and Kapton tape as a third (mechanical) attachment method. After sewing, a $1 / 2$-inch wide, one mil Kapton tape strip was placed over the stitches on the bottom of the 5 mil Kapton blanket to secure the stitches. $1 / 2$-inch wide by 3 mil aluminum foil tape was then placed over the stitches on the top side of the blanket to protect the stitches from atomic oxygen erosion. The schematic in figure 3 shows the three simultaneous methods of attachment. Doubly redundant attachment was desirable because many of the samples were fluorocarbon materials with low adhesion to the acrylic tape adhesive. Load test of the 5 mil Kapton after sewing were performed to verify the structural integrity of the flight blanket after sewing. The blanket was capable of sustaining more than 10/lbs/inch of constant tension loading for an indefinite (more than one year) period of time. A pull test on one end of each sample attached to 5 mil Kapton by the above method was conducted. All samples accepted for flight survived a one pound pull on a 3/8-inch wide sample. Adhesion tests were performed on the aluminum tape.

\section{Flight Samples and Attachment Procedure}

254 thin film samples of test materials for LEO space exposure were provided by eight research organizations. A schematic showing the placement of samples by research organization is shown in figure 4. An on-orbit photograph of the populated blanket is shown as figure 5. The samples were arranged so that sections of samples could be removed from the blanket and returned to each research organization intact after return of MISSE 5 from space. A list of flight thin film samples is available at the NASA Langley MISSE 5 website (MISSE 5, content, MISSE 5, Experiments, Materials Description).

\section{Program and Flight Schedules}

NRL and LaRC initially conceived the MISSE 5 experiment during the fall of 2002. The low solar ultraviolet space exposure part of the experiment concept/evaluation was begun in January 2003. The initial mounting system for the thin film samples was a three-ply carbon-composite thin board with staples for mechanical attachment. Extremely tight weight and packing constraints required abandoning this samples attachment method. Long term static (yield) tests were began in February, 2002 to measure Kapton blanket integrity with a range of sewing parameters (types of thread, tension, needle size, and stitch lengths) for attaching the thin film samples to the Kapton blanket. Short term load (pull) tests were performed on each candidate thin film material. Hot (373K) and cold (77K) survival tests on each candidate material were also performed. Those candidate materials that shrank, curled, or were too thick or brittle were not accepted for flight. The thin films that would not support 2.7 pounds/inch pull at the attached ends also were not accepted. The candidate thin film sample testing was completed April 22, 2003

The flight samples were attached to the 5 mil Kapton blanket during the period June 6, 2003 through June 30, 2003. The taped areas of the thin films samples blanket were pressure loaded at one pound per square inch June 30, 2003 through July 7, 2003. A pre-flight photograph of the thin films blanket is shown in figure 6. The thin film samples blanket was transported from LaRC to NRL in August 2003.

MISSE 5 was deployed August 3, 2005 and returned from space September 15, 2006 with 13 months of LEO space exposure. A post-flight photograph if the thin films blanket is shown in figure 7. 


\section{On-orbit Contamination and Atomic Oxygen Erosion of Kapton}

The MISSE 5 thin films blanket was returned to LaRC and examined in a clean room December 6 , 2006. The blanket was examined visually and with a 6x comparator under bright light. The blanket was also examined with black (ultraviolet) light. Kapton and aluminum tape environmental witness samples (figure 7) were viewed at 40x with an optical microscope. All of these examinations showed only very slight (from tape adhesive) or no on-orbit contamination.

Four approximately 1-inch diameter buttons were used to secure the blanket of thin film materials to the anti-solar side of MISSE 5. The areas adjacent to these four sites provided 1 to $2 \mathrm{~cm}^{2}$ areas of exposed and unexposed 5 mil Kapton. Matching pairs of exposed and unexposed areas of 5 mil Kapton were cut from each of the four sites. The mass eroded by atomic oxygen (mass of unexposed area minus the mass of equal exposed area) was divided by the area of the unexposed 5 mil Kapton to give the eroded mass of Kapton per unit area. These Kapton samples were weighed in a Cahn 30 microbalance. The Kapton eroded masses per unit area from the four sites are: $0.58,0.45,0.86$, and $0.84 \mathrm{mg} / \mathrm{cm}^{2}$.

\section{Conclusion}

MISSE 5 presented an opportunity to separate the solar ultraviolet LEO environmental effects from atomic oxygen effects. The solar looking primary experiment meant that an anti-solar looking side existed for the MISSE 5 PEC. A novel sample attachment method was developed and tested for the flight samples. This thin film attachment scheme used double-sided adhesive transfer tape and Kapton tap for bonding, and sewn (mechanical) sample attachment. This sample attachment scheme was flight tested and found to work very well.

\section{References}

${ }^{1}$ Harvey, G. A., Humes, D. H., and Kinard, W. H., "Mir Environmental Effects Payload and Returned Mir Solar Panel Cleanliness,” Proc. SAMPPE 44, 1999, pp 1038-1050.

${ }^{2}$ Harvey, G. A., Humes, D. H., and Kinard, W. H., “Optical Characterization of Returned Mir Solar Cells,” AIAA Space Technology Conference and Exposition, 99-4488, 1999,

${ }^{3}$ Visentine, J. et. Al., "Mir Solar Array Return Experiment," 20th AIAA Aerospace Sciences Meeting and Exfibit, AIAA 982697, 1999.

${ }^{4}$ Harvey, G. A., Humes, D. H., and Kinard, W. H., "Shuttle and Mir Special Environmental Effects and Hardware Cleanliness,” High Performance Polymers, Vol. 12, 2000, pp 65-82.

${ }^{5}$ Harvey, G. A., Kinard, W. H., and Wilson, L. A., “Outgassing of flown and Unflown Mir Solar Cells, Twenty-first Space Simulation Conference, Annapolis, MD, 2000, NASA/CP-2000-209967.

${ }^{6}$ Soares, C. E. and Mikatarian, R. R., "Mir Contamination Observations and Implications to the International Space Station, Proc. Of SPIE, Vol.4096, 2000, pp 55-65.

${ }^{7}$ Harvey, G. A. et. al., “Autononomous System for MISSE Temperature Measurements,” Space 2001 Conference and Exposition, AIAA 01-4557, Albuquerque, NM. 


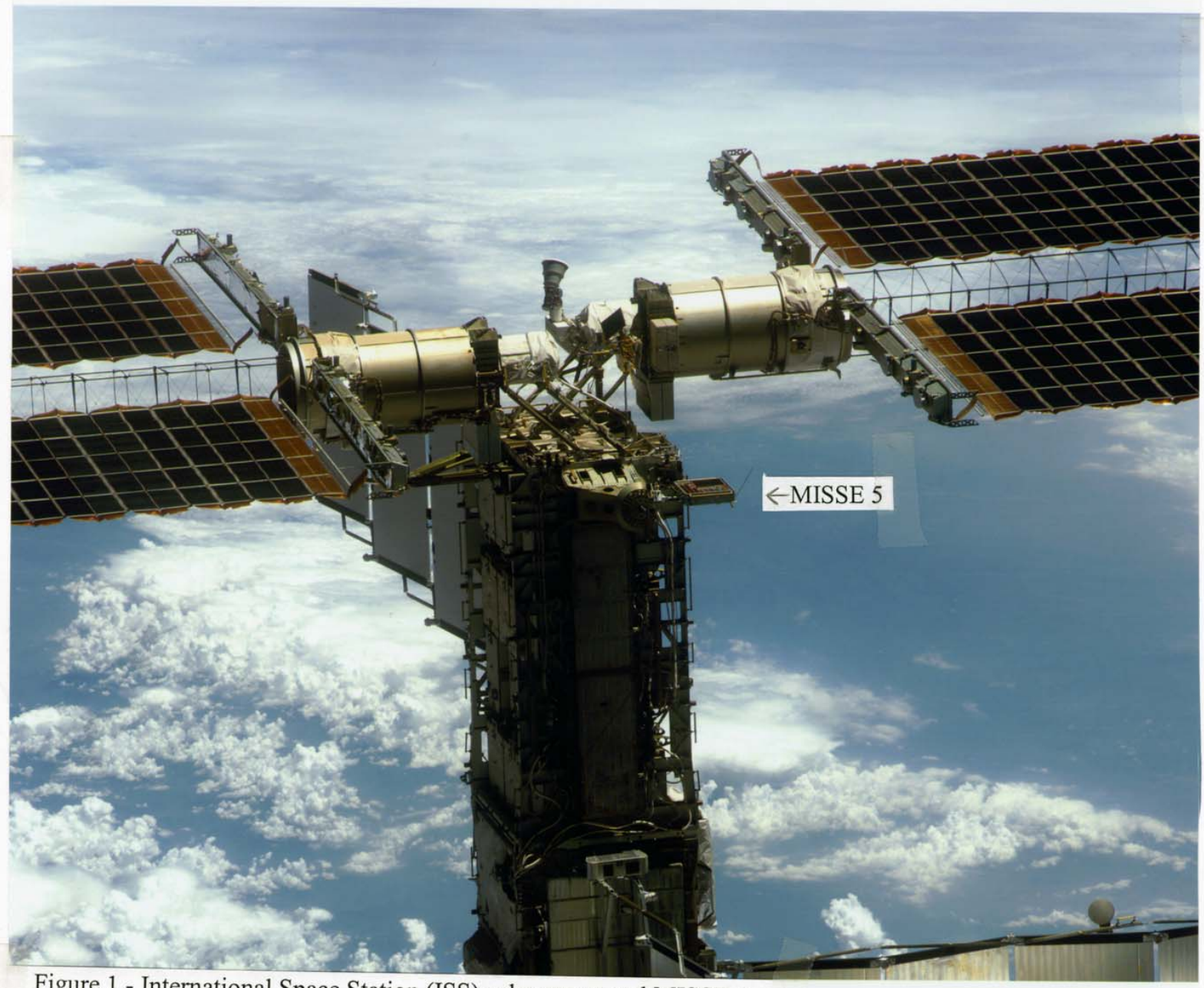

Figure 1.- International Space Station (ISS) solar arrays and MISSE 5.

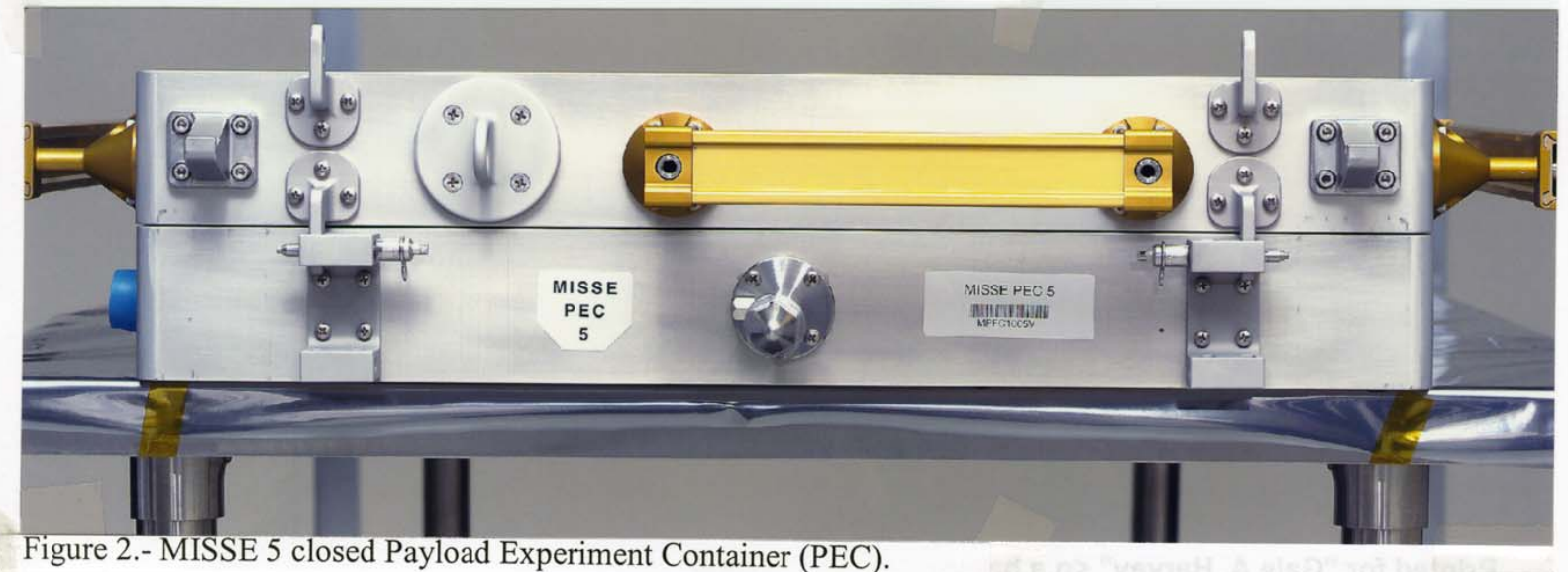




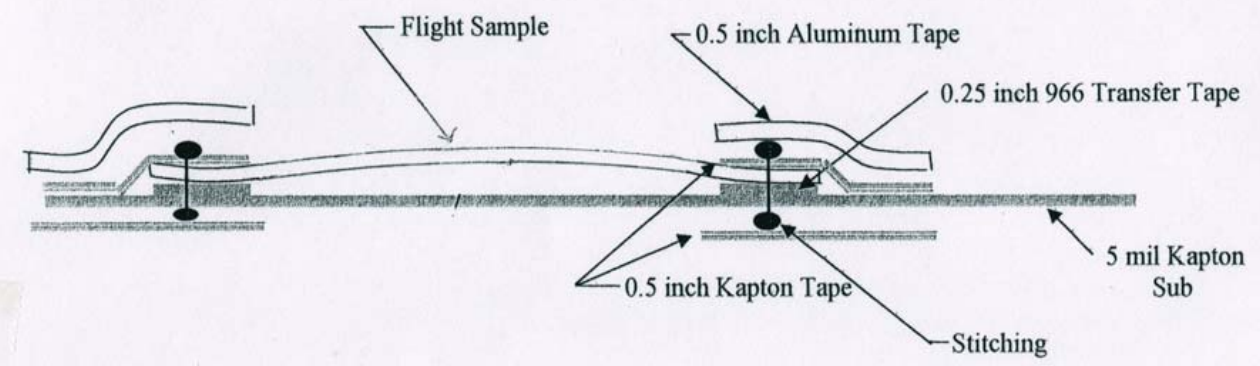

Sample Lengths:

1.5 inches

2.5 inches

3.0 inches

Figure 3. - Schematic of thin films attachment.

\begin{tabular}{|c|c|c|c|c|c|c|c|c|c|}
\hline$\underline{\mathbf{A}}$ & \begin{tabular}{c|c}
$\underset{\text { MSFC }}{\text { samples }}$ \\
$75 \times 1.5$ \\
$\longrightarrow$
\end{tabular} & B & & $\frac{\text { TEAM }}{20 \operatorname{san}}$ & $\begin{array}{l}1 \text { COOPERA } \\
\text { mples }-0.75,\end{array}$ & & NOTTOS & CALE & $\begin{array}{l}\text { LaRC } \\
1 \text { sam } \\
.375 \times \\
2.5\end{array}$ \\
\hline$\underline{\mathrm{C}}$ & $\begin{array}{c}\text { BOEING } \\
6 \text { samples } \\
0.5 \times 1.5\end{array}$ & $\mid \begin{array}{ll}D & 0 \\
\text { LaRC } & 1\end{array}$ & $\underline{\mathbf{E}}$ & & $\begin{array}{l}\text { AFRL } \\
19 \text { samples } \\
0.5 \times 1.5\end{array}$ & & & $\begin{array}{l}\mathbf{F} \\
\text { LaRd } \\
2 \mathrm{sam}\end{array}$ & $\begin{array}{l}\underline{\mathbf{G}} \\
\text { LaRC } \\
\text { I spec. }\end{array}$ \\
\hline$\underline{\mathrm{H}}$ & & & & $\begin{array}{c}\text { LaRC } \\
40 \text { sample } \\
0.375 \times 3 .\end{array}$ & & & & $\underline{I}$ & 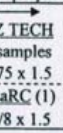 \\
\hline $\mathbf{J}$ & $\begin{array}{l}\text { MURI-C } \\
13 \text { sampl } \\
0.375 \times 1\end{array}$ & $\left.\begin{array}{l}-\mathrm{C} \\
\text { ples } \\
1.5\end{array}\right\rfloor$ & K & & & 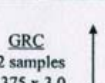 & & & \\
\hline & $\begin{array}{ll}\underline{Z} \cdot 2 & \underline{\mathbf{L}}\end{array}$ & $\underset{10 \text { samples }}{\text { LaAC }} \uparrow$ & & & & & & & \\
\hline & $\underline{\mathbf{Z}} \cdot \mathbf{3}$ & $0.375 \times 1.5$ & $\underline{\mathrm{M}}$ & & & GRC $\uparrow$ & & & \\
\hline & $\underline{\mathbf{N}}$ & $\mid$\begin{tabular}{l|l}
$\underline{\mathbf{X}} \underset{2 \text { samples }}{\text { GRC }}$ \\
$0.5 \times 15.5$
\end{tabular} & & & & $\begin{array}{l}4.5 \text { samples } \\
0.5\end{array}$ & & & \\
\hline & $\begin{array}{l}\frac{\text { safe }}{5 \text { samples }} \\
0.75 \times 1.5 \\
\longleftrightarrow\end{array}$ & & $\begin{array}{c}\text { P } \frac{\text { MURI-C }}{6 \text { samples }} \\
\longleftrightarrow\end{array}$ & 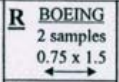 & $\stackrel{\text { T }}{\text { GRC }}$ & $\underline{\mathbf{U}}$ & $\underline{\underline{v}}_{\underline{G R C}}$ & & $\begin{array}{l}\text { TECH } \\
\text { ample } \\
5 \times 15\end{array}$ \\
\hline & & 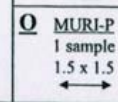 & 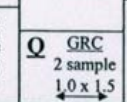 & $\underline{\mathbf{S}} \underset{\substack{\text { GRC } \\
2 \text { samples } \\
1,0 \times 1.5 \\
\longrightarrow}}{\longrightarrow}$ & $\stackrel{\substack{7 \text { samples } \\
0.5 \times 1.5}}{\longleftrightarrow}$ & $\stackrel{\substack{7 \text { samples } \\
0.5 \times 1.5}}{\longleftrightarrow}$ & $\stackrel{\substack{7 \text { samples } \\
0.5 \times 1.5}}{\longleftrightarrow}$ & 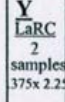 & \\
\hline
\end{tabular}

Figure 4. - Blanket location of thin films samples.

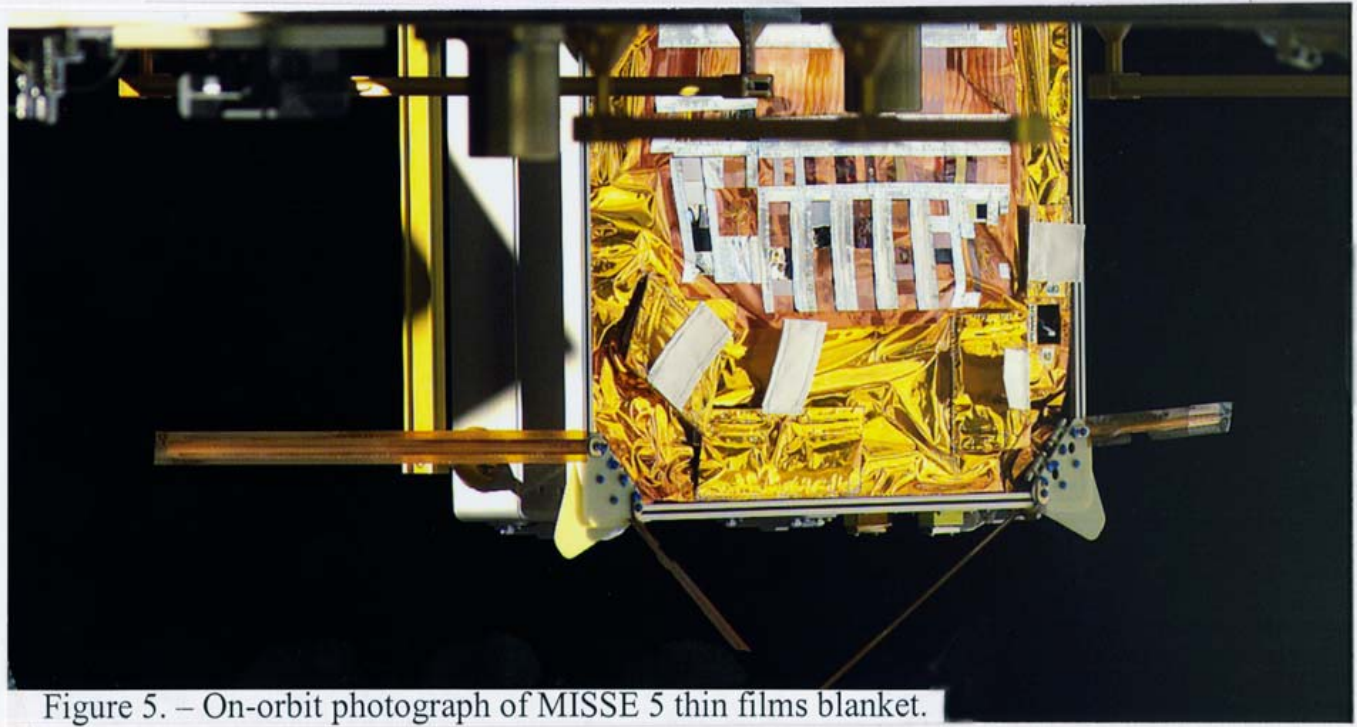

Figure 5. - On-orbit photograph of MISSE 5 thin films blanket. 


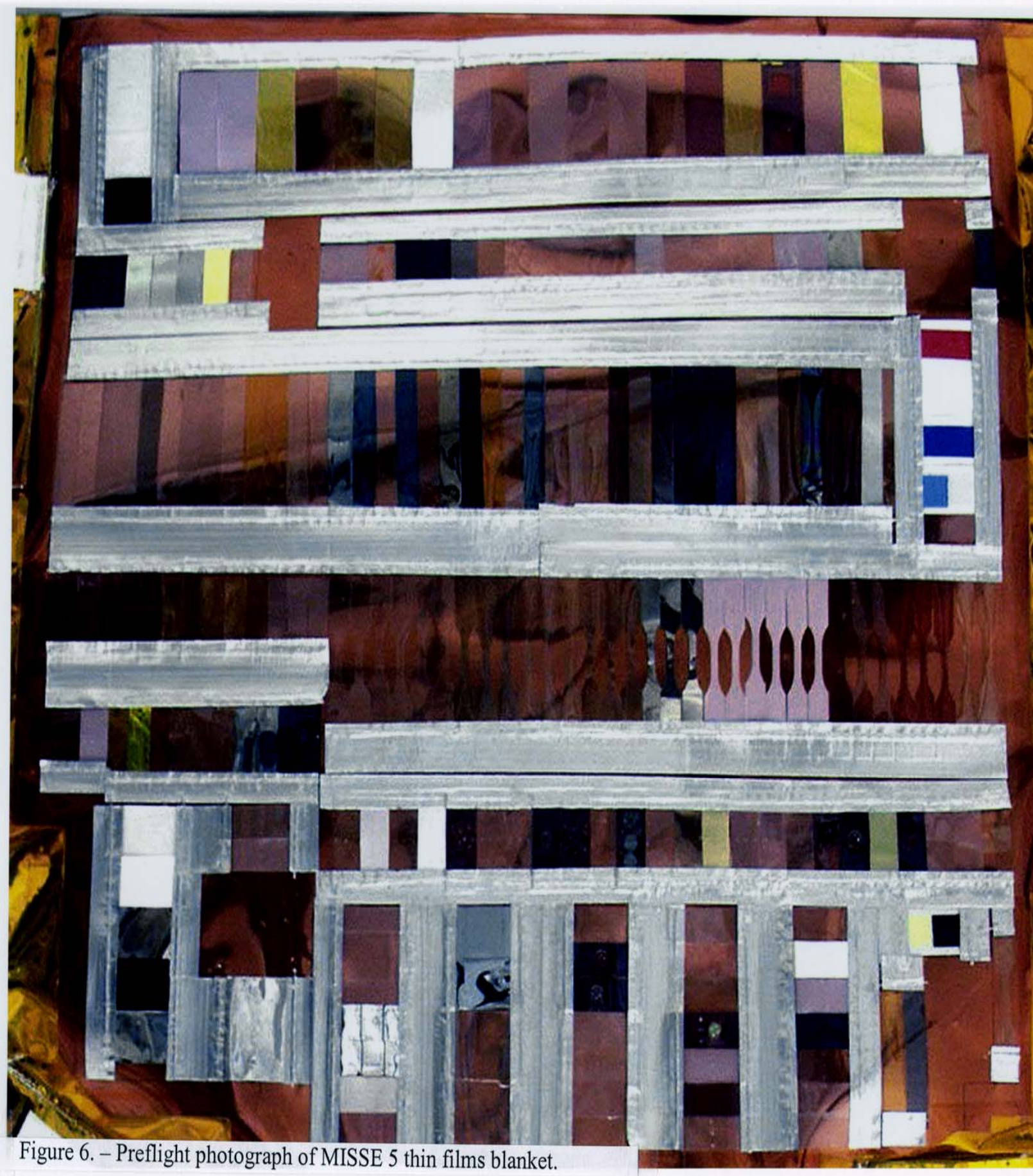




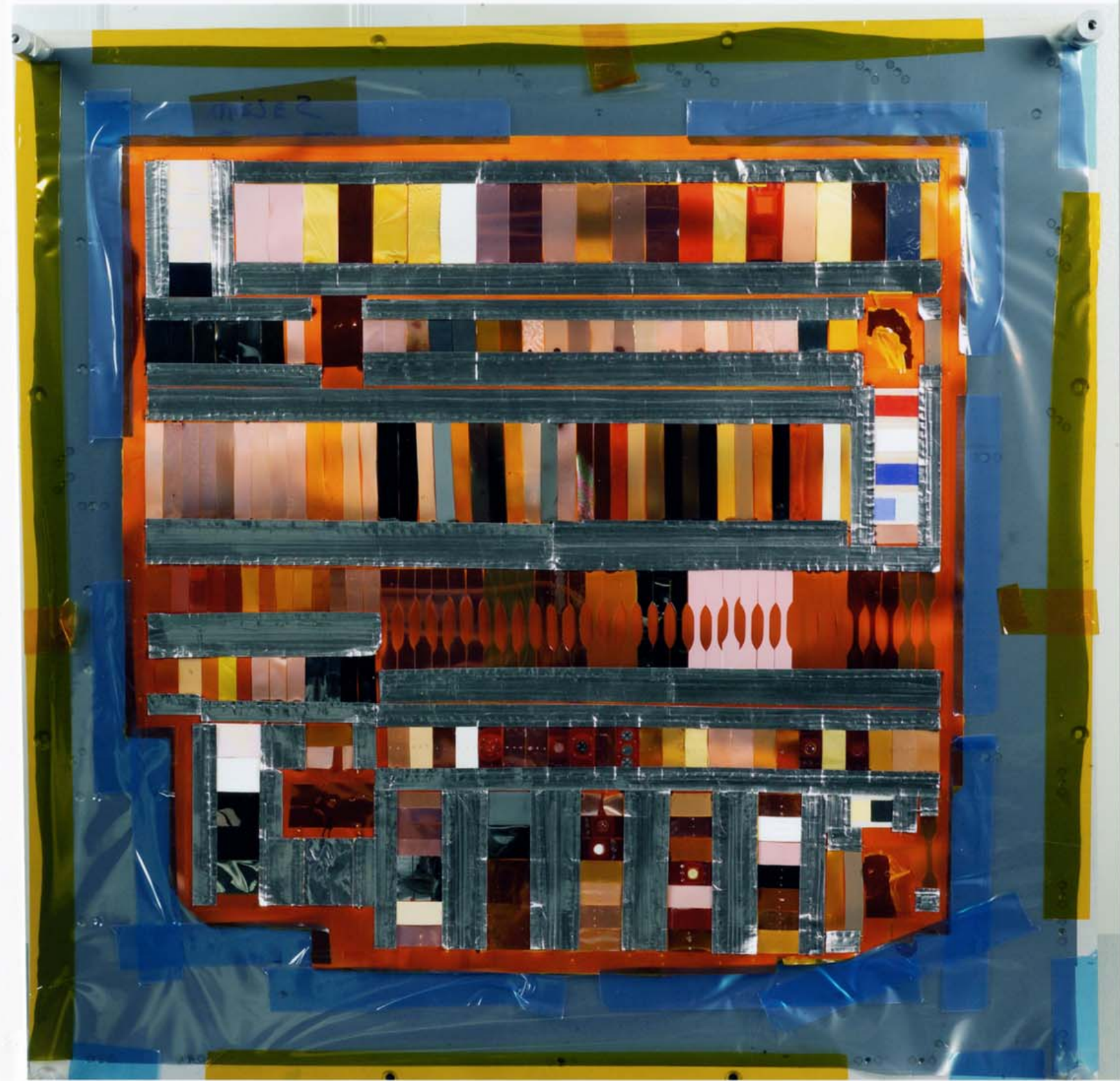

Figure 7. - Postflight photograph of MISSE 5 thin films blanket.

Langley Research Center Hampton, Virginia 23681-0001 